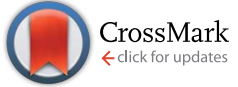

Cite this: RSC Adv., 2017, 7, 17473

\title{
Enhancement of thermal stability for perovskite solar cells through cesium doping $\dagger$
}

\author{
Guangda Niu, Wenzhe Li, Jiangwei Li, Xingyao Liang and Liduo Wang*
}

Organic-inorganic hybrid perovskite solar cells are found to be sensitive to moisture, oxygen, UV light, light soaking, heat, electric field, etc. Among all these factors, thermal stability is one of the most challenging concerns affecting PSCs stability, since it is hard to avoid a temperature increase for solar cells during operation. In this work, we systematically studied the thermal stability of $\mathrm{Cs}_{x} \mathrm{MA}_{1-x} \mathrm{Pbl}_{3}$ film and solar cells. The introduction of Cs into the precursor solution would inevitably accelerate the film deposition rate, resulting in decreased grain size and more Cs atoms in the film than in the precursors. The study on thermal stability illustrated that perovskite degradation was highly related to the amount of oxygen in the air. A small amount of Cs doping $(x=0.09)$ was beneficial for better thermal stability. In addition, Cs doping also enhanced the device performance. The improvement of short-circuit currents came from the increased film thickness, which was due to the faster deposition rate for Cs doped samples. Besides, Cs doping was vital to suppress the trap states in the film since the trap states were related to halide deficiency during thermal annealing. At last, the final performance of $\mathrm{Cs}_{0.09} \mathrm{MA}_{0.91} \mathrm{Pbl}_{3}$ reached $18.1 \%$, with a $J_{\mathrm{SC}}$ of $22.57 \mathrm{~mA} \mathrm{~cm}^{-2}, V_{\mathrm{OC}}$ of $1.06 \mathrm{~V}$, FF of 0.76 .

Received 21st December 2016 Accepted 10th March 2017

DOI: 10.1039/c6ra28501e

rsc.li/rsc-advances stability toward an electric field, which is also denoted as the typically observed hysteresis phenomenon, could be solved by suppressing the trap states of perovskites, by using $\mathrm{PC}_{61} \mathrm{BM}$ or other fullerene derivatives. ${ }^{\mathbf{1 6 , 1 7}}$

Currently, from our views, thermal stability and light soaking are the most challenging concerns affecting PSCs stability, since it is hard to avoid temperature increase and light illumination for solar cells during operation. Formamidinium $\left(\mathrm{HC}\left(\mathrm{NH}_{2}\right)_{2}\right)$, abbreviated as FA, has been demonstrated more stable than methylammonium $\left(\mathrm{CH}_{3} \mathrm{NH}_{3}\right.$, shortened as MA) under high temperature. ${ }^{18,19}$ However, as an organic molecules, degradation could still be observed for FA-based perovskite, especially when oxygen was present, which was caused by the oxidation of FA. Moreover, FA is also more sensitive to moisture than MA due to its high hygroscopicity, thus requiring more rigorous encapsulation and increasing the cost. In terms of the intrinsic property, Cs-based perovskite should exhibit higher thermal stability than FA- and MA-counterparts. Some recent papers indeed found that $\mathrm{CsPbBr}_{3}, \mathrm{CsPbI}_{2} \mathrm{Br}, \mathrm{CsPbIBr}{ }_{2}$ could endure harsh conditions with temperature as high as $300{ }^{\circ} \mathrm{C}^{20-22}$ However, due to the non-ideal band gaps $(>1.7 \mathrm{eV})$, the PCE for Cs-based perovskite is relatively lower than $\mathrm{MAPbI}_{3}$ and $\left(\mathrm{MAPbBr}_{3}\right)_{x}\left(\mathrm{FAPbI}_{3}\right)_{1-x}$. For single junction solar cells, researchers started to utilize mixture of Cs-MA, Cs-FA, Cs-MAFA etc. , to compose perovskite. ${ }^{23-25}$ The role of Cs was found to be effective to stabilize the black phase of $\mathrm{FAPbI}_{3}$, decrease trap states, and benefit device performance. However, there is still no detailed studies on thermal stability of Cs-based perovskite materials.
Department of Chemist
mail.tsinghua.edu.cn

$\dagger$ Electronic supplementary information (ESI) available. See DOI: 10.1039/c6ra28501e 
In addition, previous studies have demonstrated that halide deficiency are responsible for the observed trap states. ${ }^{26,27}$ Henry Snaith and co-workers found that hypophosphorous acid (HPA) could successfully suppress the halide deficiency-induced trap states, since HPA could reduce the oxidized $\mathrm{I}_{2}$ in precursors back to $\mathrm{I}^{-}$, resulting in an improved stoichiometry in the perovskite crystal. During film annealing process, iodide could also loss due to the evaporation of MAI or oxidation. ${ }^{28}$ Based on the above assumption, we believe better thermal stability of perovskite will be beneficial for the suppression of defect states caused by halide deficiency.

In this work, we systematically studied the thermal stability of $\mathrm{Cs}_{x} \mathrm{MA}_{1-x} \mathrm{PbI}_{3}$ film and solar cells fabricated from one-step spin-coating method. It was surprisingly found that the composition of the deposited film deviated from the precursors, with much more Cs atoms deposited onto the film. This was probably due to the limited solubility of CsI compared to MAI and $\mathrm{PbI}_{2}$. Then we studied the thermal stability of $\mathrm{MAPbI}_{3}$ and $\mathrm{Cs}_{x} \mathrm{MA}_{1-x} \mathrm{PbI}_{3}$ film in nitrogen, dry air, and humid air, and found the decomposition of the film was highly accelerated by oxygen. In addition, the thermal stability for $\mathrm{Cs}_{x} \mathrm{MA}_{1-x} \mathrm{PbI}_{3}$ film with $x=0.09$ and 0.20 is better than pure $\mathrm{MAPbI}_{3}$. However, when the content further increased, the thermal stability rapidly decreased, which is beyond our expectation. Timeresolved photoluminescence and electrochemical impedance spectra demonstrated the reduced defect density after Cs introduction. The final performance of $\mathrm{Cs}_{x} \mathrm{MA}_{1-x} \mathrm{PbI}_{3}$ reached $18.1 \%$, with a $J_{\mathrm{SC}}$ of $22.57 \mathrm{~mA} \mathrm{~cm}^{-2}, V_{\mathrm{OC}}$ of $1.06 \mathrm{~V}$, FF of 0.76 . In addition, the thermal stability of the unencapsulated devices for $x=0.09$ was also significantly improved compared to $\mathrm{MAPbI}_{3}$.

\section{Results and discussions}

Firstly, we prepared perovskite films with different Cs content. During the experiments, one-step method was used to construct the films, since according to our experience, two-step deposition typically led to needle-like crystals atop the film. CsI, MAI, and $\mathrm{PbI}_{2}$ were mixed together in the precursor solution, dissolving into a mixed solvent of GBL : DMSO $=7: 3$. Cs salts were hard to dissolve, thereby we heated the whole solution at $60{ }^{\circ} \mathrm{C}$. X-ray photoelectron spectroscopy (XPS) was used to quantitatively study the content of Cs in the films (Fig. S1 $\dagger$ ). As shown in Table 1, Cs content in the films were always higher than the precursors, which was due to the preferentially precipitated Cs atoms considering its low solubility. The composition of the film was denoted as $\mathrm{Cs}_{x} \mathrm{MA}_{1-x} \mathrm{PbI}_{3}$, where $x$ represented the content of Cs.

Then we studied the thermal stability of the prepared films by firstly recording the relative absorption at $700 \mathrm{~nm}$ for each film, as shown in Fig. 1. The films were heated at $120^{\circ} \mathrm{C}$ for 3 hours exposing to air. The relative absorption (RA) was calculated by the following formula: $\mathrm{RA}=$ (absorption after thermal treatment)/(absorption before thermal treatment). It was found that when Cs content was 0.09, the films exhibited better stability than control sample. However, as the Cs content was higher than 0.23 , the retained absorption at $700 \mathrm{~nm}$ was even lower than the control sample, implying worse stability. The abnormal phenomenon was probably due to that when Cs content was high, $\mathrm{CsPbI}_{3}$ would segregate from the film, and $\mathrm{CsPbI}_{3}$ would easily change from black perovskite phase (cubic) to yellow non-perovskite phase (orthorhombic). The yellow phase has a band gap of $2.82 \mathrm{eV}$, thereby exhibiting no absorption at $700 \mathrm{~nm}$. It should also be noted that the film exhibited better stability under nitrogen. When storing in nitrogen atmosphere, we further increased the temperature to $150{ }^{\circ} \mathrm{C}$ for 3 hours, and found the $x=0$ sample was still black (Fig. 1d). There are two possible reasons for the degradation, one is oxygen, and another is moisture. We used a gas mixture of $\left(V_{\mathrm{N}_{2}}: V_{\mathrm{O}_{2}}=4: 1\right)$ to simulate "dry air". The films still turned yellow during heating at $120{ }^{\circ} \mathrm{C}$ for 3 hours. The above results indicated the instability of perovskite was caused by the oxidation of $\mathrm{CH}_{3} \mathrm{NH}_{2}$, which was consistent with the previous reports. ${ }^{29}$ The partial replacement of MA with Cs atoms could improve the stability, which was probably due to the suppressed thermal loss and oxidation of MA through less MA occupation in A site and compressed crystal structure. We chose $x=0.09$ as the most stable film to fabricate solar cells.

XRD patterns and SEM images were used to study the composition and morphology change of the film before and after thermal degradation. As shown in Fig. 2a, all the films demonstrated strongest intensity along $\langle 110\rangle /\langle 002\rangle$ directions. Consistent with our previous results, as Cs doping increased, the peak for $(112) /(200)$ planes became more obvious, which was due to that Cs atoms would preferentially precipitate and result in preferred crystal orientation along the more thermodynamically stable directions of $\langle 112\rangle /\langle 200\rangle \cdot{ }^{23}$ After thermal treatment (Fig. 2b), there was an additional new peak at $12.6^{\circ}$, which attributed to $\mathrm{PbI}_{2}$. For the control sample $(x=0)$, the peak for

Table 1 Cs content in precursors and in films, determined by XPS

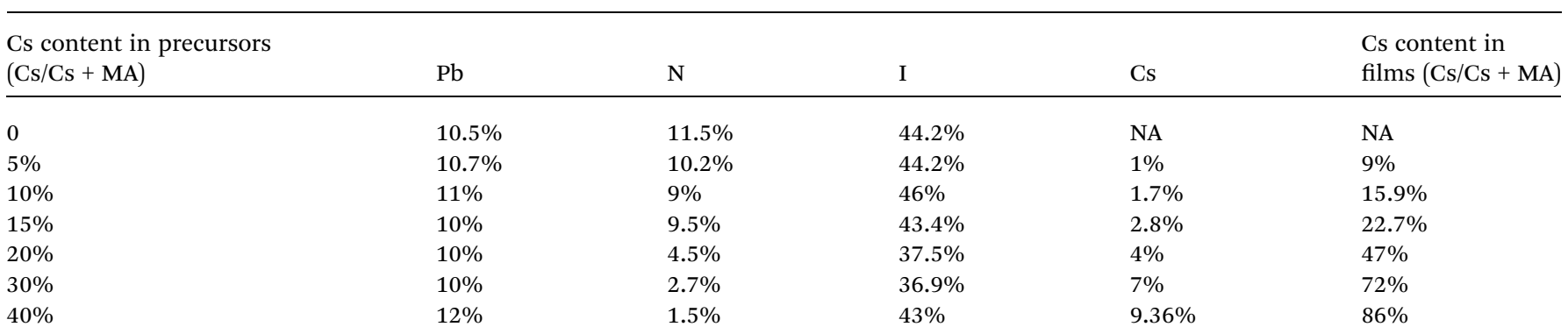



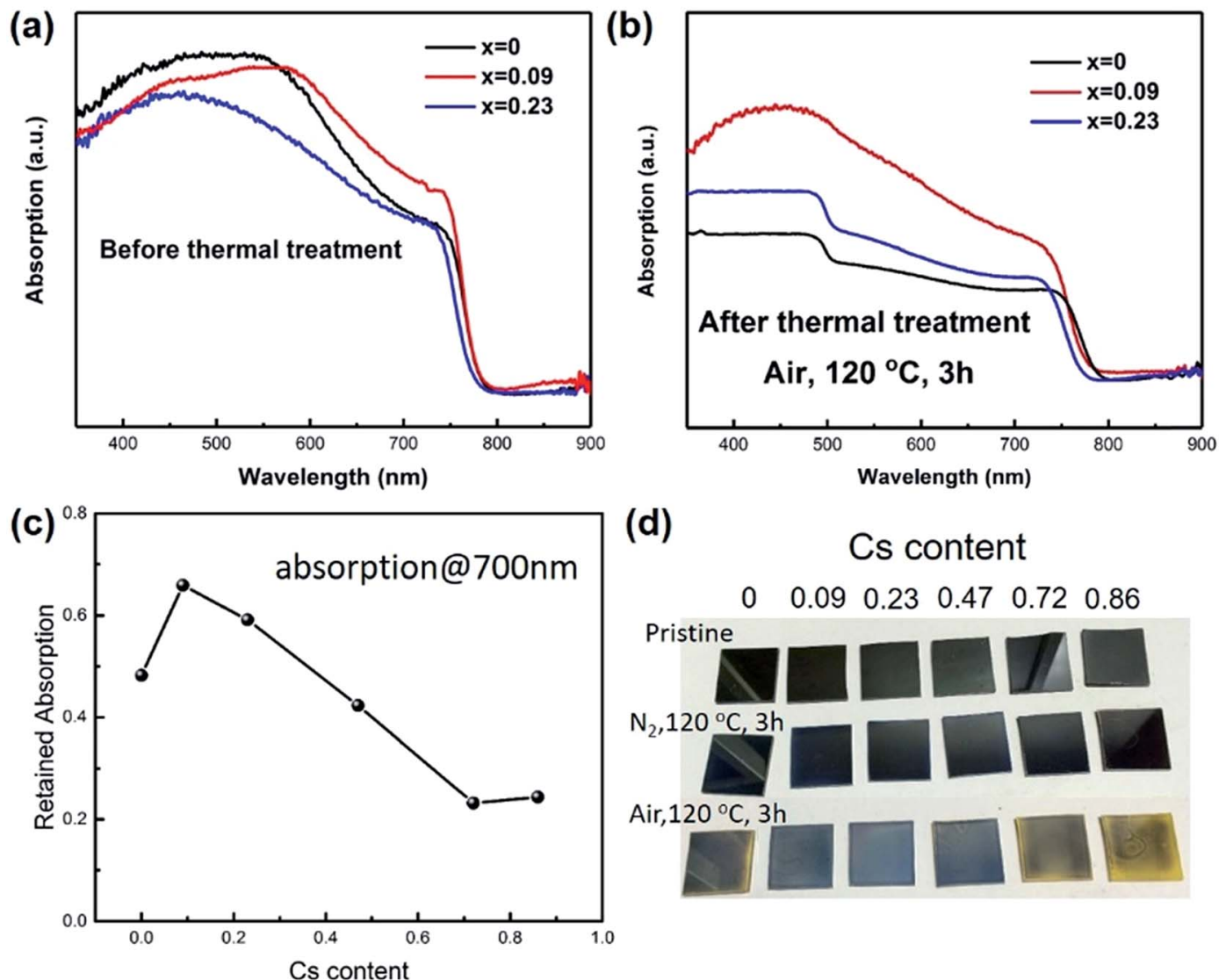

(d)

\section{Cs content}

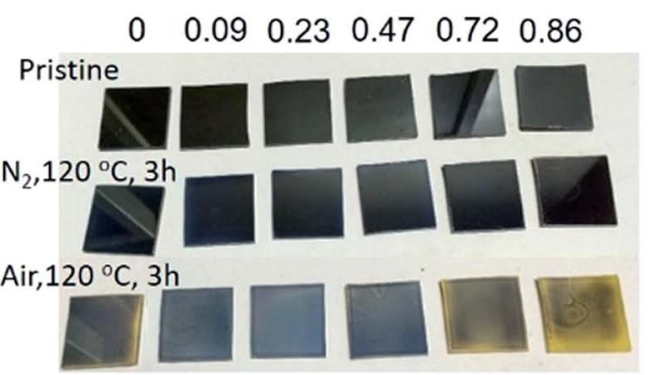

Fig. 1 Thermal stability study of perovskite films with different Cs content. (a) Perovskite films with compositions of $\mathrm{Cs}_{x} \mathrm{MA}_{1-x} \mathrm{Pbl}_{3}$ before thermal treatment, where $x$ represents Cs content. (b) Perovskite films after thermal treatment at $120{ }^{\circ} \mathrm{C}$ for 3 hours exposing to air. (c) Retained absorption at $700 \mathrm{~nm}$ for perovskite films with $x$ ranging from 0 to 0.86 . (d) Photographs of perovskite films exposing to different atmosphere.

$\mathrm{PbI}_{2}$ was much higher than perovskite, demonstrating most of $\mathrm{MAPbI}_{3}$ has degraded to $\mathrm{PbI}_{2}$. For $x=0.09$, the formation of $\mathrm{PbI}_{2}$ was effectively suppressed, due to the better thermal stability. For $x=0.23$, in contrast, the peak for perovskite was even lower than that of $x=0$.

Fig. $2 \mathrm{c}$ and $\mathrm{d}$ shows the morphology of the films. Before thermal treatment, all the films were flat with no pinholes, while Cs content could lead to smaller grain size, probably due to the increased nucleation sites in the early stage of film formation. In contrast, after thermal treatment, the films became rugged, especially for $x=0$. The pits and pinholes were caused by the loss of MAI or $\mathrm{CH}_{3} \mathrm{NH}_{2}$, leaving the film recrystallized as $\mathrm{PbI}_{2}$. When Cs was introduced into the film, the pinholes was effectively suppressed. In addition, as Cs content increased, the pinholes became smaller due to the much more stable A site (Cs) in the films and decreased crystal volume.

We assembled perovskite solar cells with $x=0$ and $x=0.09$, since if $x>0.09$, the thermal stability was not good enough. As shown in Fig. 3a and b, the cross-sectional SEM images exhibited that the thickness of perovskite $(x=0.09)$ was $\sim 500 \mathrm{~nm}$, including the mesoporous $\mathrm{TiO}_{2}$ layer and top perovskite layer, higher than that of $x=0(405 \mathrm{~nm})$. During the experiment, all the parameters were kept the same except the composition of precursor solution. The higher thickness of $x=$ 0.09 was probably due to the increased film formation rate when
Cs was introduced into the film. If the film formation rate was fast, more perovskite would precipitate out when chlorobenzene was added onto the film to quench the precursor solution. Due to the increased film thickness, the short-circuit current $\left(J_{\mathrm{SC}}\right)$ of $x=0.09$ was higher than that for $x=0$. As shown in Table 2 and Fig. 3c, the champion device of $x=0.09$ showed a $J_{\mathrm{SC}}$ of $22.57 \mathrm{~mA} \mathrm{~cm}^{-2}$, a $V_{\mathrm{OC}}$ of $1.06 \mathrm{~V}, \mathrm{FF}$ of 0.76 , leading to a final power conversion efficiency of $18.1 \%$. In contrast, the champion device of control sample exhibited a $J_{\mathrm{SC}}$ of $20.59 \mathrm{~mA}$ $\mathrm{cm}^{-2}$, a $V_{\mathrm{OC}}$ of $1.04 \mathrm{~V}$, FF of 0.74 , and a PCE of $15.8 \%$. Fig. 3d shows the IPCE spectra of the champion devices. Although Cs atoms could inevitably increase the band gap of perovskite, the absorption region was almost the same for $x=0$ and 0.09 due to the small doping ratio. The integrated photocurrent for $x=$ 0 and 0.09 was 18.6 and $19.9 \mathrm{~mA} \mathrm{~cm}{ }^{-2}$, respectively, slightly lower than the value derived from $J-V$ curves. The reason is that our devices exhibited hysteresis effect, while IPCE recorded the steady state current. We have also averaged data from 12 devices to obtain statistic information. The average $J_{\mathrm{SC}}$ was increased from $20.34 \pm 1.20 \mathrm{~mA} \mathrm{~cm}{ }^{-2}$ for $x=0$ to $22.42 \pm 0.33 \mathrm{~mA} \mathrm{~cm}^{-2}$ for $x=0.09$. Additionally, besides the increase of $J_{\mathrm{SC}}$ after Cs introduction, the fill factors have also been increased from 0.70 \pm 0.02 to $0.74 \pm 0.01$. During this work, we employed mesoporous $\mathrm{TiO}_{2}$ as anode and found hysteresis effect for the fabricated devices (Fig. S3†). Further improvement on 

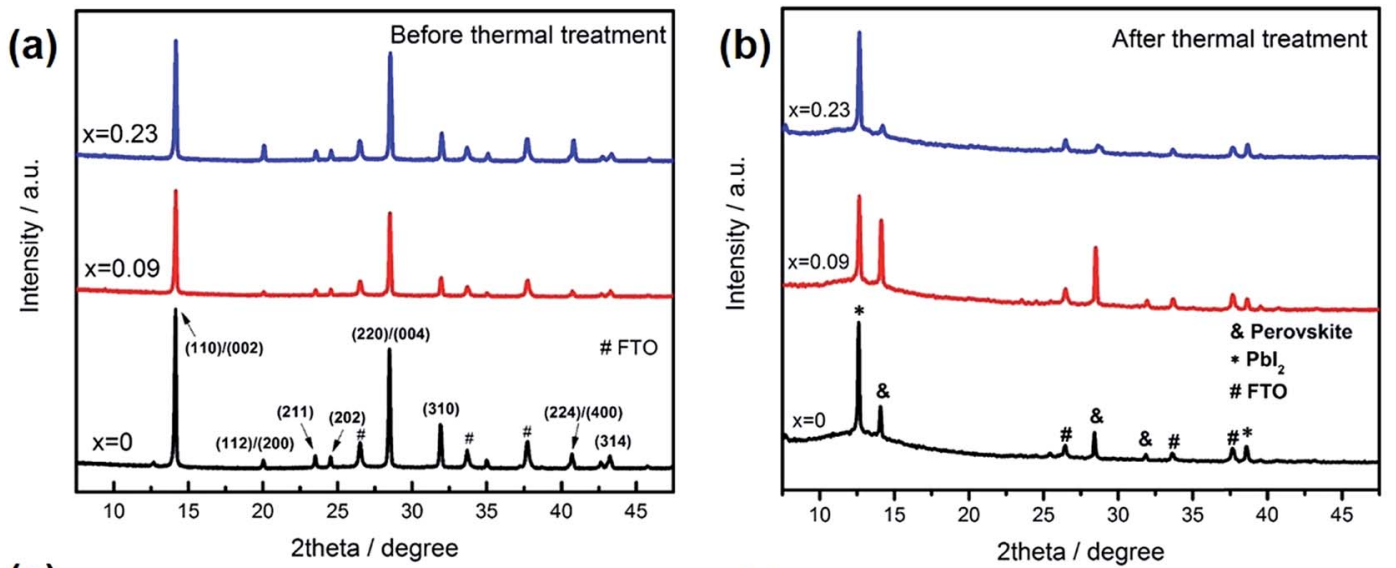

(c)

\section{Before thermal treatment}
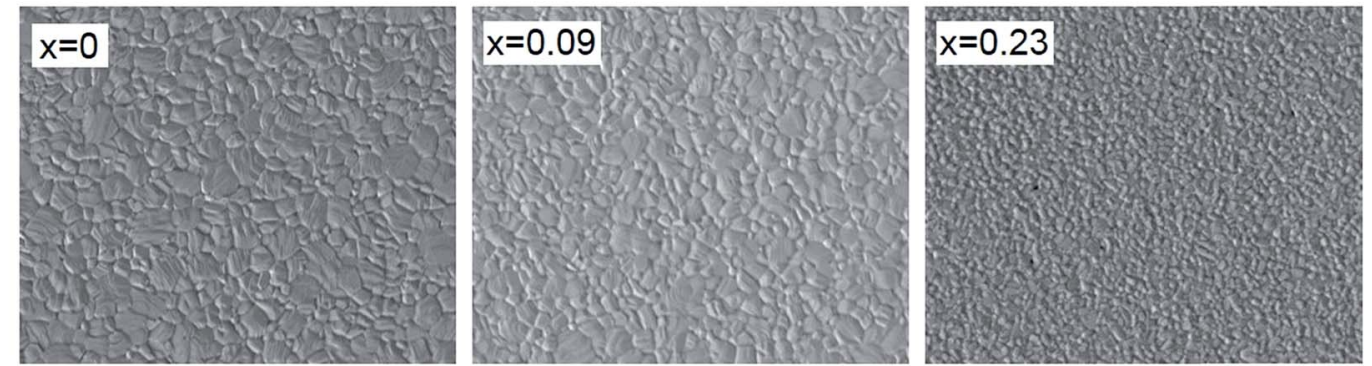

(d)
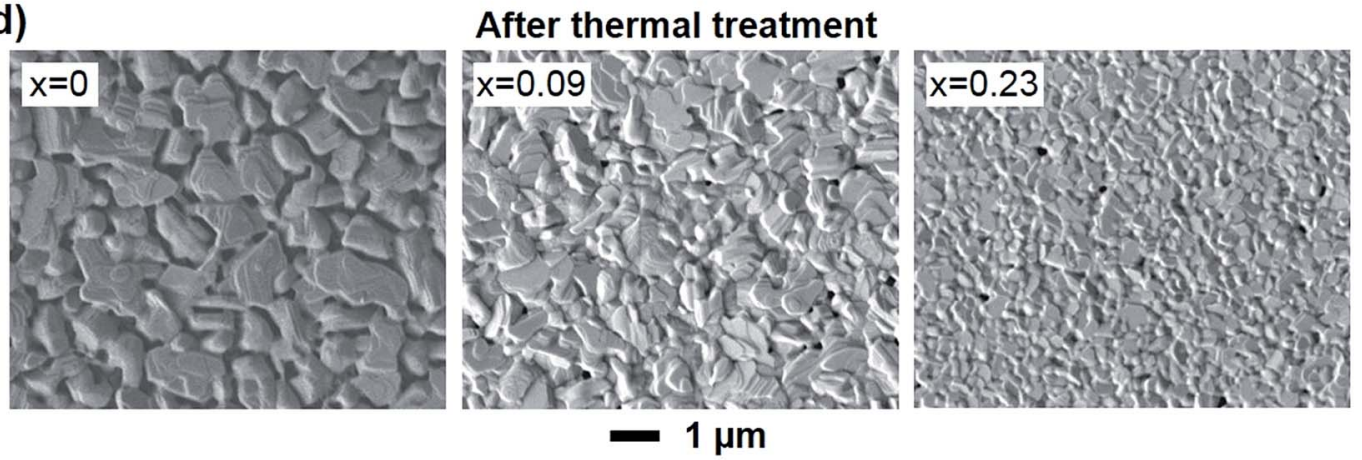

Fig. 2 Structure analysis of perovskite films. (a, b) XRD patterns for $\mathrm{Cs}_{x} \mathrm{MA}_{1-x} \mathrm{~Pb}{ }_{3}$ before and after thermal treatment. (c, d) Top-down view SEM images of perovskite films before and after thermal treatment.

suppressing hysteresis, such as using $\mathrm{C}_{60}$ or other fullerene derivatives, is undergoing. In order to illustrate the change of $\mathrm{FF}$, we measured electrochemical impedance spectra (EIS) to study the internal electron recombination process. The response under light illuminations was analyzed at different applied voltages. Two semicircles and a low frequency feature are existing in the spectra (Fig. S2 $\dagger$ ). The first arc at higher frequencies attributes to the charge transfer in hole transport materials (HTM). The second one at lower frequencies is caused by the electron recombination at the interface of $\mathrm{TiO}_{2} /$ perovskite/HTM. The low frequency feature is due to slow charge transport, which is not related to the device physics, and is not included in the analysis in this paper. The impedance spectra was fitted with a simplified equivalent circuit from the typical transmission line model for dye sensitized solar cells, as shown in the inset of Fig. S2. $\dagger^{23}$ The $R_{\text {rec }}$ from the second arc represents the charge recombination barrier at the interface of
$\mathrm{TiO}_{2} /$ perovskite/HTM (Fig. 3e). It is acknowledged that the decreased trap states in the perovskite film could lead to reduced charge recombination. In this work, the charge recombination was suppressed when Cs was introduced into the film, which would be further verified through photoluminescence (PL) decay and X-ray photoelectron spectra (XPS). In addition, the charge lifetime could be obtained by $R_{\text {rec }} \times C_{\text {rec }}$ from the second arc. It is found that the lifetime was also increased after Cs introduction (Fig. 3f). It could also be seen that as the $V_{\text {appl }}$ increased, the recombination resistance and lifetime lowered, because of the upshift of the Fermi level of $\mathrm{TiO}_{2}$ and promoted electron transfer to perovskite and HTM.

In order to explain the charge recombination effect by Cs introduction, we measured XPS spectra for the films (Fig. 4a). There are two main peaks for $\mathrm{Pb} 4 \mathrm{f}$ spectra, assigning to $\mathrm{Pb} 4 \mathrm{f} 7 /$ 2 and $\mathrm{Pb} 4 \mathrm{f} 5 / 2$. For $x=0$ sample, the peaks at $138.4 \mathrm{eV}$ and $143.2 \mathrm{eV}$ are due to $\mathrm{Pb}$ element from perovskite. The presence of 
(a)

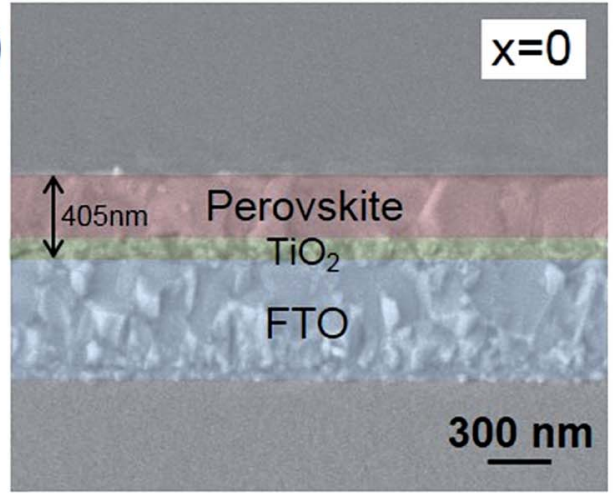

(c)
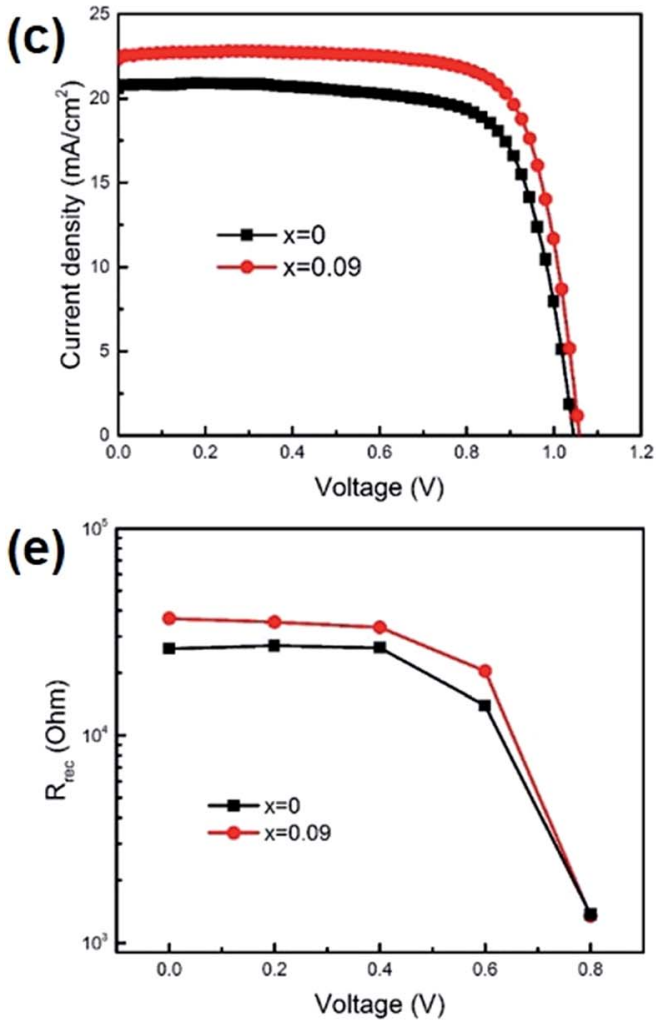

(b)

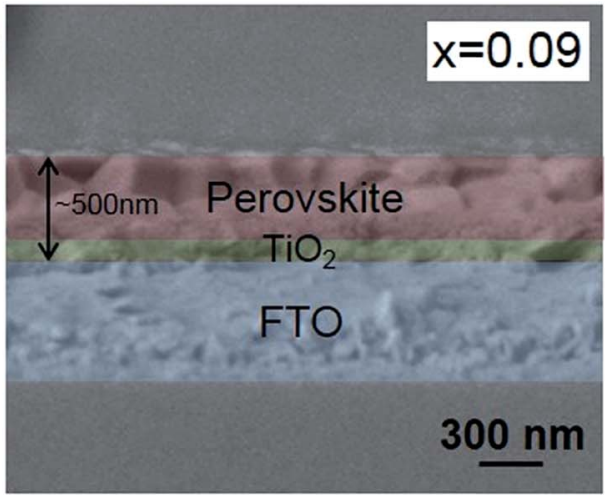

(d)

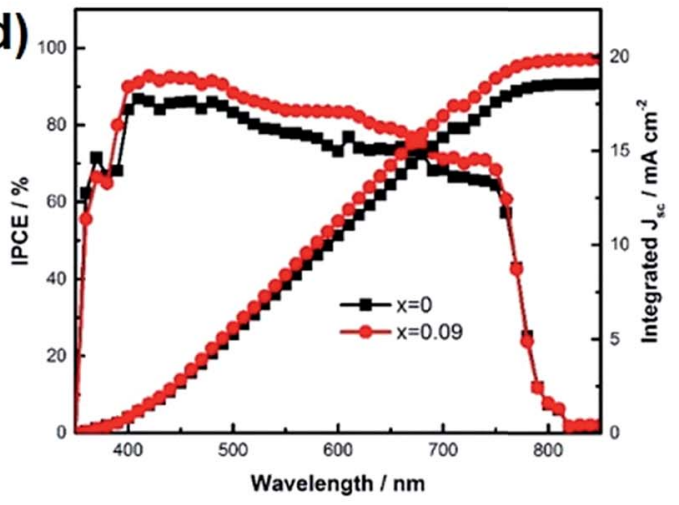

(f)

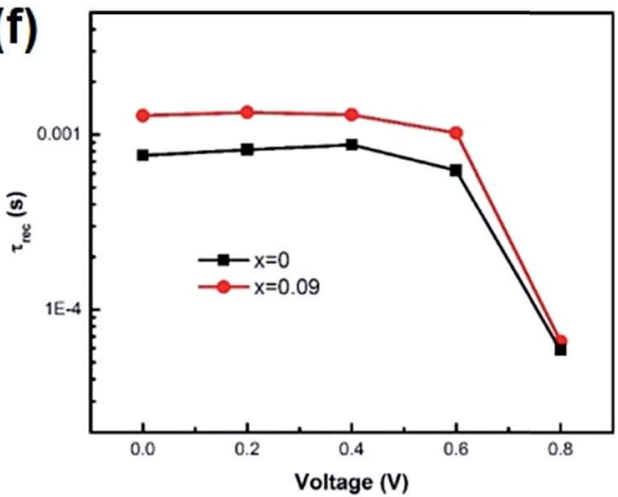

Fig. 3 (a, b) Cross-sectional SEM images of perovskite films with $x=0$ and 0.09 . (c) $J-V$ characteristics of champion devices with different Cs content. (d) IPCE and integrated photocurrent for the champion devices. (e) Recombination resistance derived from electrochemical impedance spectra (EIS). (f) Electron recombination time from EIS spectra.

Table 2 Performance summary for perovskite solar cells with different Cs content

\begin{tabular}{lllll}
\hline & $J_{\mathrm{SC}}\left(\mathrm{mA} \mathrm{cm}^{-2}\right)$ & $V_{\mathrm{OC}}(\mathrm{V})$ & $\mathrm{FF}$ & $\eta(\%)$ \\
\hline$x=0$ & $20.34 \pm 1.2$ & $1.05 \pm 0.01$ & $0.70 \pm 0.02$ & $14.9 \pm 1.3$ \\
Champion & 20.59 & 1.04 & 0.74 & 15.8 \\
$x=0.09$ & $22.42 \pm 0.33$ & $1.05 \pm 0.01$ & $0.74 \pm 0.01$ & $17.5 \pm 0.5$ \\
Champion & 22.57 & 1.06 & 0.76 & 18.1
\end{tabular}

small peaks at $136.9 \mathrm{eV}$ and $141.3 \mathrm{eV}$ could be assigned to metallic $\mathrm{Pb}\left(\mathrm{Pb}^{0}\right)$, which was due to unsaturated $\mathrm{Pb}$, according to recent studies. Henry Snaith and co-workers demonstrated that the presence of unsaturated $\mathrm{Pb}$ atoms was related to the iodide deficiencies, and metallic lead species could act as recombination sites, leading to poor performance. ${ }^{26}$ In our assumption, during thermal annealing process, the loss of iodide was accompanied with the loss of methyl ammonium. When we replaced some MA with Cs atoms, due to the better thermal stability and thus less loss of molecular groups from A site and iodide atoms, unsaturated $\mathrm{Pb}$ was effectively suppressed. For XPS spectra of $x=0.09$, there are no additional peaks from $\mathrm{Pb}^{0}$. Furthermore, we also measured transient photoluminescence spectra to study the defect density in the film (Fig. 4b). The decay curves could be well fitted by a biexponential decay function. The fast component is attributed to the surface recombination, while the slow component is caused by the recombination in the bulk of perovskite. We average the two components according to their amplitude to obtain the 

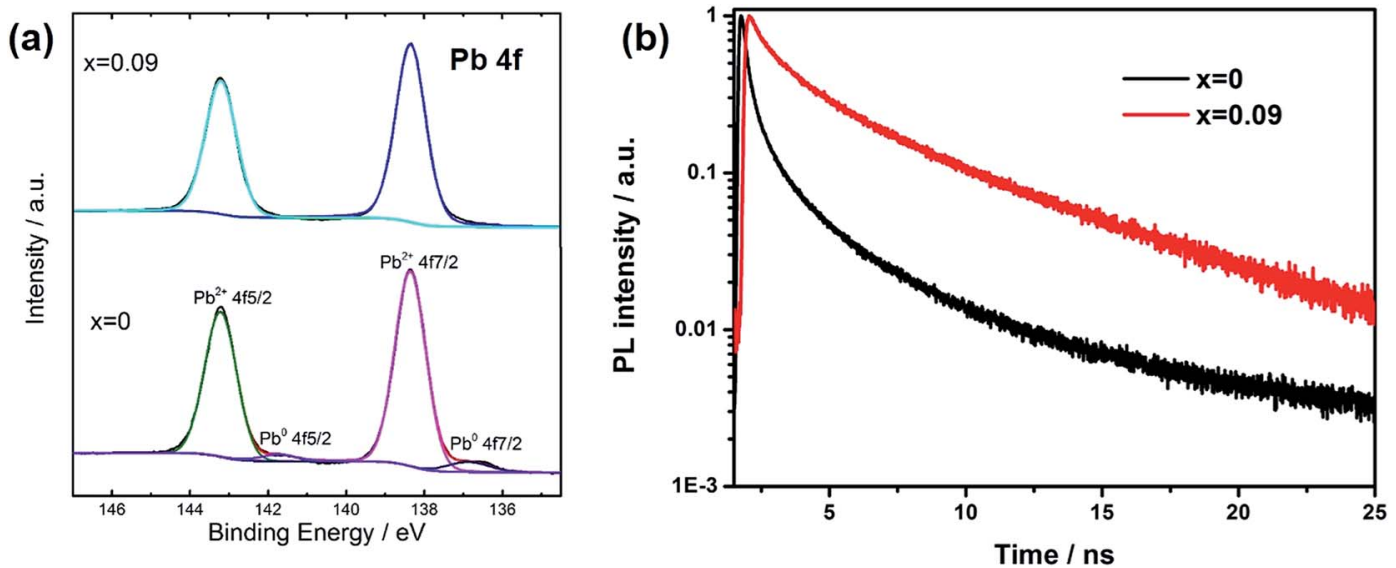

Fig. 4 (a) XPS study of Pb4f for $x=0$ and 0.09 films. (b) Transient PL spectra for perovskite films with different Cs content.

lifetime of carriers. The average corresponding decay time was 1.9 and 2.9 ns for $x=0$, and 0.09 respectively, as shown in the inset of Fig. 4b. The increased lifetime when Cs was introduced into the film reflected the reduction of trap density, which was indicative of fewer non-radiative recombination sites.

At last, we compared the thermal stability of assembled perovskite solar cells for $x=0$ and 0.09 , as shown in Fig. 5 . The accelerated stability of the devices is evaluated in air at $85{ }^{\circ} \mathrm{C}$ without encapsulation. Each time before measurement for $J-V$ curves, the devices were cooled down to room temperature naturally. For $x=0$, less than $40 \%$ of the original performance was maintained after $60 \mathrm{~min}$ aging test. In contrast, for $x=0.09$, nearly $80 \%$ of the initial performance was retained after the same durability test. The data were averaged from 6 devices in one batch. There are two causes for the performance declination, one is coming from the degradation of perovskite, and the other one is from the degradation of spiro-MeOTAD under heat treatment. The glass transition temperature of spiro-MeOTAD is around $125{ }^{\circ} \mathrm{C}^{11}$ We believe mixture of Cs and MA indeed

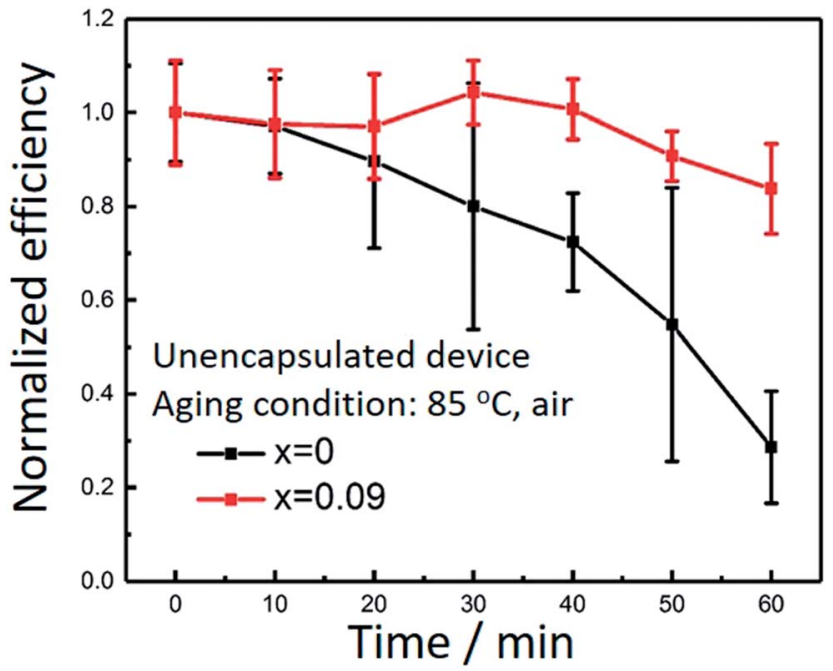

Fig. 5 Thermal stability of assembled perovskite solar cells from Cs doping and undoped perovskite. improved the thermal stability. However, the existence of spiroMeOTAD would inevitably lower the overall stability. Better stability toward thermal conditions could be obtained by replacing spiro-MeOTAD with other stable hole transport materials.

\section{Conclusions}

In a word, we have successfully fabricated perovskite films with composition of $\mathrm{Cs}_{x} \mathrm{MA}_{1-x} \mathrm{PbI}_{3}$. The introduction of Cs into the precursor solution would inevitably accelerate the film deposition rate. The results were that the grain size became smaller and the film contained more Cs atoms than in the precursors. The study on thermal stability illustrated that perovskite degradation was highly related with oxygen in air. Small amount of Cs doping $(x=0.09)$ was beneficial for the better thermal stability. In addition, Cs doping also enhanced the device performance. The improvement of short-circuit currents came from the increased film thickness, which was due to the faster deposition rate for Cs doped sample. Besides, Cs doping was vital to suppress the trap states in the film since the trap states was related to the halide deficiency during thermal annealing. At last, the final performance of $\mathrm{Cs}_{0.09} \mathrm{MA}_{0.91} \mathrm{PbI}_{3}$ reached $18.1 \%$, with a $J_{\mathrm{SC}}$ of $22.57 \mathrm{~mA} \mathrm{~cm}^{-2}, V_{\mathrm{OC}}$ of $1.06 \mathrm{~V}, \mathrm{FF}$ of 0.76 . In addition, the thermal stability of the unencapsulated devices for $x=0.09$ was also significantly improved compared to $\mathrm{MAPbI}_{3}$.

\section{Experimental details}

\section{Solar cell fabrications}

The $\mathrm{TiO}_{2}$ compact layer was deposited onto FTO glass through atomic layer deposition (Beneq TFS 200) documented in previous reports. The $\mathrm{mp}-\mathrm{TiO}_{2}$ layer was prepared by depositing nanocrystalline $\mathrm{TiO}_{2}$ paste (18NRT from Dyesol Company; diluted to $\mathrm{w} / \mathrm{w} 14.3 \%$ ) onto the compact layer at $6000 \mathrm{rpm}$ for $30 \mathrm{~s}$, followed by heating at $500{ }^{\circ} \mathrm{C}$ for $1 \mathrm{~h}$. The perovskite precursors were prepared by dissolving specific amounts of $\mathrm{PbI}_{2}$, MAI, and CsI in the mixed solvent $(\gamma$-butyrolactone : DMSO = 
$7: 3 \mathrm{vol} \%)$. The total concentration of $\mathrm{Pb}$ was set as $0.96 \mathrm{M}$ for all the solutions. The solutions were then coated onto the substrate by two consecutive spin-coating steps, at $1500 \mathrm{rpm}$ for $10 \mathrm{~s}$, and $5000 \mathrm{rpm}$ for $30 \mathrm{~s}$. During the second step, $0.3 \mathrm{~mL}$ chlorobenzene was poured onto the substrate. Then the film was heated at $90{ }^{\circ} \mathrm{C}$ for $10 \mathrm{~min}$. Spiro-MeOTAD solution was prepared by dissolving $102.7 \mathrm{mg}$ spiro-MeOTAD in $1 \mathrm{~mL}$ chlorobenzene, to which $9.85 \mu \mathrm{L}$ 4-tert-butyl pyridine and $42.22 \mu \mathrm{L}$ lithium bis(trifluoromethanesulfonyl)imide solution (170 mg LITFSI in $1 \mathrm{~mL}$ acetonitrile) were added. Spiro-MeOTAD was deposited on the substrate at $2000 \mathrm{rpm}$ for $45 \mathrm{~s}$. Then the films were left in air overnight. Finally, $50 \mathrm{~nm}$ gold electrode were thermally evaporated under vacuum of $\sim 10^{-6}$ Torr, at a rate of $\sim 0.2 \AA \mathrm{s}^{-1}$.

\section{Characterization}

X-ray diffraction (XRD) spectra was measured with smart LAB instruments $\mathrm{Cu} \mathrm{K} \alpha$ beam $(\lambda=1.54 \AA)$. UV-Vis absorption spectra were obtained with a Hitachi U-3010 spectroscope. SEM images were measured by JEOL JSM-7401F and TEM images by Hitachi HT7700 with an acceleration voltage of $100 \mathrm{kV}$. The composition of the film was measured by ICP-AES (Thermo IRIS intrepid II). $J-V$ curves were measured by a Keithley 2400 source meter under one sun illumination ( $\mathrm{AM} 1.5 \mathrm{G}, 100 \mathrm{~mW} \mathrm{~cm}^{-2}$ ), simulated by a solar simulator (ORIEL 81193) calibrated with an NRELcalibrated silicon solar cell. External quantum efficiency (EQE) spectra were recorded by a setup, consist of a xenon light source, a monochromator, and a potentiostat. EIS were measured by an electrochemical workstation (Zahner, CIMPS) with frequency from 10 to $10^{6} \mathrm{~Hz}$ under applied voltage with an amplitude of $10 \mathrm{mV}$ under light condition. The active area of each cell was $0.16 \mathrm{~cm}^{2}$ with a mask of $0.09 \mathrm{~cm}^{2}$. Time-resolved PL decay was measured by a FV1200, excited at $488 \mathrm{~nm}$.

\section{Acknowledgements}

The research was funded by the National Natural Science Foundation of China under Grant no. 51273104 and 91433205.

\section{References}

1 A. Kojima, K. Teshima, Y. Shirai and T. Miyasaka, J. Am. Chem. Soc., 2009, 131, 6050.

2 M. M. Lee, J. Teuscher, T. Miyasaka, T. N. Murakami and H. J. Snaith, Science, 2012, 338, 643.

3 http://www.nrel.gov/ncpv/images/efficiency_chart.jpg.

4 H. S. Kim, C. R. Lee, J. H. Im, K. B. Lee, T. Moehl, A. Marchioro, S. J. Moon, R. Humphry-Baker, J. H. Yum, J. E. Moser, M. Grätzel and N. G. Park, Sci. Rep., 2012, 2, 591.

5 J. Burschka, N. Pellet, S.-J. Moon, R. Humphry-Baker, P. Gao, M. K. Nazeeruddin and M. Grätzel, Nature, 2013, 499, 316.

6 H. Zhou, Q. Chen, G. Li, S. Luo, T.-b. Song, H.-S. Duan, Z. Hong, J. You, Y. Liu and Y. Yang, Science, 2014, 345, 542.

7 W. S. Yang, J. H. Noh, N. J. Jeon, Y. C. Kim, S. Ryu, J. Seo and S. I. Seok, Science, 2015, 348, 1234.

8 H.-S. Kim, S. H. Im and N.-G. Park, J. Phys. Chem. C, 2014, 118, 5615.
9 J. H. Noh, S. H. Im, J. H. Heo, T. N. Mandal and S. I. Seok, Nano Lett., 2013, 13, 1764.

10 G. Niu, W. Li, F. Meng, L. Wang, H. Dong and Y. Qiu, J. Mater. Chem. A, 2014, 2, 705.

11 G. Niu, X. Guo and L. Wang, J. Mater. Chem. A, 2015, 3, 8970. 12 M. Grätzel, Nat. Mater., 2014, 13, 838.

13 X. Li, M. Tschumi, H. Han, S. S. Babkair, R. A. Alzubaydi, A. A. Ansari, S. S. Habib, M. K. Nazeeruddin, S. M. Zakeeruddin and M. Grätzel, Energy Technol., 2015, 3, 551.

14 F. Bella, G. Griffini, J.-P. Correa-Baena, G. Saracco, M. Grätzel, A. Hagfeldt, S. Turri and C. Gerbaldi, Science, DOI: $10.1126 /$ science.aah4046.

15 J. You, L. Meng, T.-B. Song, T.-F. Guo, Y. Yang, W.-H. Chang, Z. Hong, H. Chen, H. Zhou, Q. Chen, Y. Liu, N. D. Marco and Y. Yang, Nat. Nanotechnol., 2016, 11, 75.

16 W. Chen, Y. Wu, Y. Yue, J. Liu, W. Zhang, X. Yang, H. Chen, E. Bi, I. Ashraful, M. Grätzel and L. Han, Science, 2015, 350, 944.

17 Y. Shao, Y. Yuan and J. Huang, Nat. Energy, 2016, 1, 15001. 18 J. W. Lee, D. H. Kim, H. S. Kim, S. W. Seo, S. M. Cho and N. G. Park, Adv. Energy Mater., 2015, 5, 1501310.

19 G. E. Eperon, S. D. Stranks, C. Menelaou, M. B. Johnston, L. M. Herz and H. J. Snaith, Energy Environ. Sci., 2014, 7, 982. 20 G. E. Eperon, G. M. Paternò, R. J. Sutton, A. Zampetti, A. A. Haghighirad, F. Cacialli and H. J. Snaith, J. Mater. Chem. A, 2015, 3, 19688.

21 R. E. Beal, D. J. Slotcavage, T. Leijtens, A. R. Bowring, R. A. Belisle, W. H. Nguyen, G. F. Burkhard, E. T. Hoke and M. D. McGehee, J. Phys. Chem. Lett., 2016, 7, 746.

22 Q. Ma, S. Huang, X. Wen, M. A. Green and A. W. Y. HoBaillie, Adv. Energy Mater., 2016, 6, 1502202.

23 G. Niu, H. Yu, J. Li, D. Wang and L. Wang, Nano Energy, 2016, 27, 87.

24 M. Saliba, M. Tsisuke, J.-Y. Seo, K. Domanski, J.-P. CorreaBaena, M. K. Nazeeruddin, S. M. Zakeeruddin, W. Tress, A. Abate, A. Hagfeldt and M. Grätzel, Energy Environ. Sci., 2016, 9, 1989.

25 C. Yi, J. Luo, S. Meloni, A. Boziki, N. Ashari-Astani, C. Gratzel, S. M. Zakeeruddin, U. Röthlisberger and M. Grätzel, Energy Environ. Sci., 2016, 9, 656.

26 W. Zhang, S. Pathak, N. Sakai, T. Stergiopoulos, P. K. Nayak, N. K. Noel, A. A. Haghighirad, V. M. Burlakov, D. W. deQuilettes, A. Sadhanala, W. Li, L. Wang, D. S. Ginger, R. H. Friend and H. J. Snaith, Nat. Commun., 2015, 6, 10030.

27 N. Pellet, P. Gao, G. Gregori, T.-Y. Yang, M. K. Nazeeruddin, J. Maier and M. Grätzel, Angew. Chem., Int. Ed., 2014, 53, 3151.

28 E. J. Juarez-Perez, Z. Hawash, S. R. Raga, L. K. Ono and Y. Qi, Energy Environ. Sci., 2016, 9, 3406.

29 B. Conings, J. Drijkoningen, N. Gauquelin, A. Babayigit, J. D'Haen, L. D'Olieslaeger, A. Ethirajan, J. Berbeeck, J. Manca, E. Mosconi, F. D. Angelis and H.-G. Boyen, Adv. Energy Mater., 2015, 5, 1500477. 